\title{
Estudio descriptivo de actividad del banco y registro de donantes de médula ósea de la región de Murcia (sureste de España) (1994-2004)
}

\author{
G. M. ROJAS MONTERO, M. R. ÁLVAREZ LÓPEZ, A. LÓPEZ BERMEJO', \\ M. R. MOYA QUILES, M. MURO AMADOR \\ Servicio de Inmunología. Hospital Universitario Virgen de la Arrixaca. Murcia. \\ ${ }^{1}$ Fundación Española para la Lucha contra la Leucemia. Caravaca de la Cruz. Murcia
}

DESCRIPTIVE STUDY OF ACTIVITY OF THE BONE MARROW DONOR REGISTRY AND BANK FROM THE MURCIA REGION (SOUTHEAST OF SPAIN) (1994-2004)

\begin{abstract}
RESUMEN
Objetivo: Realizar un estudio descriptivo de la actividad del banco y registro de donantes de médula ósea de la región de Murcia.

Sujetos y método: Constituido por los donantes disponibles en el Banco de médula desde 1994 hasta $2004(\mathrm{n}=3137)$. El estudio consiste en un análisis del número de donantes, su procedencia y, las búsquedas realizadas. Los donantes se tiparon por técnicas serológicas de microlinfocitoxicidad, y moleculares de PCR-SSO y -SSP.

Resultados: El banco dispone de 3.137 donantes voluntarios tipados en baja y alta resolución, realizando un total de 680 búsquedas de donante. La procedencia de los donantes según las áreas de salud en que esta dividida la Comunidad de Murcia fue: área I (28\%), área II (18\%), área III (23\%), área IV (6\%), área VI (10\%) y otras provincias (12\%).

Conclusiones: Observamos un aumento exponencial del número de donantes anuales, así como un aumento muy notable de las búsquedas por año, especialmente el 2004.
\end{abstract}

PALABRAS CLAVE: Registro de donantes. Trasplante de médula ósea. Tipaje HLA. Donante no emparentado.
ABSTRACT

Objective: To perform a descriptive study of the activity of the Bank of marrow donors from Murcia Region.

Subjects and methods: All donors in the Bank of bone marrow from 1994 until 2004 (n=3137). This study analysed the number of donors, their origin and, performed donor searches activity. Donors were typed by serological microlymphocytotoxicity and molecular PCR-SSO and PCR-SSP techniques.

Results: The Bank of bone marrow has 3,137 voluntary donors typed in low- and high-resolution. A total of 680 donor searches have been realized. The origin of the donors according to several Areas of Health in which the Autonomous Community of Murcia is divided, is the following one: Area I (28\%), Area II (18\%), Area III (23\%), Area IV (6\%), Area VI $(10 \%)$ and other provinces $(12 \%)$.

Conclusions: An increase is observed in the number of annual donors as well as an increase very marked of donor searches that are realized every year, especially in 2004.

KEY WORDS: Donor registry. Bone marrow transplant. HLA typing. Unrelated donor.

Rojas Montero GM, Álvarez López MR, López Bermejo A, Moya Quiles MR, Muro Amador M. Estudio descriptivo de actividad del banco y registro de donantes de médula ósea de la región de Murcia (sureste de España) (1994-2004). An Med Interna (Madrid)

2006; 23: 525-528.

\section{INTRODUCCIÓN}

Nuestra sociedad sufre hoy día un gran impacto social y económico de las enfermedades oncohematológicas. En éstas, muchas veces se ha de recurrir al trasplante de medula ósea (TMO) como solución terapéutica.

Normalmente, el donante para el trasplante alogénico es un hermano del paciente, HLA idéntico u otro familiar (con haplotipos frecuentes).

Pero el donante también puede ser una persona sin consanguinidad con el paciente; son los donantes no relacionados $o$ no emparentados (DNE), los cuales pueden obtenerse mediante la búsqueda a través de los bancos y registros de donantes voluntarios de todo el mundo (1).

Debido a la imposibilidad de realizar en muchas ocasiones un trasplante autólogo y a la falta de familiares compatibles con el paciente, se hace necesario el disponer de un potente $\mathrm{y}$ efectivo banco de DNE. Así, en 1988, la Fundación Internacional Josep Carreras puso en marcha, en España, el registro de donantes voluntarios de médula ósea (REDMO). Esta fundación tiene un acuerdo con el Ministerio de Sanidad y Consumo y con todas las Comunidades Autónomas.

El REDMO realiza su gestión como miembro de la WMDA (World Marrow Donor Association), relacionándose con todos

Trabajo aceptado: 23 de junio de 2006

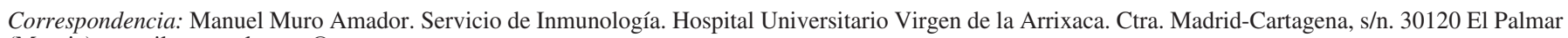
(Murcia).e-mail: manuel.muro@carm.es 
los Registros existentes en el listado internacional de donantes (BMDW-Bone Marrow Donors Worldwide), y que forman parte del Programa Internacional de Trasplante de médula ósea no emparentado. Así, los 90 registros existentes en el mundo disponen ya de 10 millones de DNE. El REDMO (con 53.000 DNE) esta en sexta posición del ranking de Europa y Estados Unidos, por detrás de Alemania, Estados Unidos, Italia, Bélgica y Francia.

El banco y registro de donantes de médula ósea existente en el Hospital Universitario Virgen de la Arrixaca de Murcia forma parte de este registro REDMO y es el centro de referencia de la Comunidad Autónoma de la Región de Murcia. Este Banco tiene más de diez años de vida, y en esta comunicación se esbozará un resumen de su actividad durante este periodo, analizando el número de DNE y tipajes HLA realizados, la procedencia de DNE dentro y fuera de la región y las búsquedas de DNE efectuadas.

\section{SUJETOS Y MÉTODOS}

El estudio que se describe a continuación se ha llevado a cabo en el Servicio de Inmunología del Hospital Universitario Virgen de la Arrixaca de la región de Murcia. La duración del presente estudio es de diez años, los años que tiene de vida este Banco y Registro de DMO; y el estudio consiste en una recopilación de su actividad constante durante este tiempo.

Los DNE reclutados son personas sanas de entre 18 y 55 años de edad. Además, el $80 \%$ de estos DNE es también donante de sangre, aunque hay también un gran número de familiares de pacientes que se han convertido en DNE. Cada DNE voluntario es archivado con el consentimiento informado firmado por él mismo, el facultativo que informa de los requisitos del REDMO y un testigo, y con una clave de identificación personal.

Limitaciones y criterios de selección en la búsqueda de $D N E$. El elevado polimorfismo del sistema HLA limita las probabilidades de encontrar un DNE HLA idéntico (2). Así, la probabilidad de encontrar un donante que no sea familiar es de 1/20.000 a 1/40.000 habitantes. A pesar de las trabas, se tarda una media de 50 días para encontrar un posible DNE, con el apoyo de otros registros de DMO del mundo.

Hoy en día se acepta como DNE ideal a aquel que comparte por lo menos los mismos alelos que el paciente en los loci HLA-A, -B, -C y -DRB1, dejándose a elección de cada centro el ampliar dicho grado de tipificación (3). En el supuesto de existir más de un DNE compatible se siguen una serie de criterios para la selección del DNE más conveniente al paciente, como edad del donante, sexo, peso y grupo ABO (4-7).

Técnicas de tipificación HLA clase I y clase II, y nivel de resolución. Para la caracterización inmunogenética de los DNE, se separaron células mononucleares de sangre periférica por gradiente de densidad y, posteriormente, se llevo a cabo tiraje HLA clase I (HLA-A y -B) por técnicas de microlinfocitotoxicidad con placas propias o comerciales (OneLambda Inc., Canoga Park, CA), como previamente publicado (8).

En los casos en que el tipaje serológico no dio resultados concluyentes se realizo tipaje molecular de baja resolución por técnicas moleculares de PCR-SSP (Dynal, Oslo, Noruega y OneLambda). También se ha realizado PCR-SSP en bastantes de los DNE que se ha pedido desde el REDMO la definición clara (split) de la especificidad.
En todos ellos, se ha procedido a la extracción y cuantificación del ADN para posteriores estudios de ampliación de tipaje en el momento que se precise. Así, se extrajo ADN genómico de linfocitos de sangre con técnicas basadas en digestión con proteinasa K (Boehringer Mannheim, Germany), como previamente publicado (8).

Además, en el principio del Banco los tipajes HLA de clase II (HLA-DR y -DQ) se realizaron por técnicas serológicas, las cuales se abandonaron en 1995 por métodos de ADN, utilizando PCR con sondas oligonucleotídicas específicas de secuencia (SSOs), que consiste en la amplificación genómica de las secuencias polimórficas de HLA-DRB1 y -DQB1, y un panel de sondas marcadas con digoxigenina para la definición alélica, como publicado (9). A partir de 1996, los tipajes moleculares de baja y alta resolución HLA de clase II se realizan por técnicas de PCR-SSP y -SSO (Dynal y OneLambda).

Mantenimiento de la base de datos. Los datos referentes a los DNE voluntarios son tratados confidencialmente, con clave de acceso restringida. La información y determinaciones efectuadas a los DNE se actualizan continuamente en la base de datos (Microsoft Access, Seattle, WA). Los análisis estadísticos se realizaron con SSPS v12.0 (SPSS Inc., Chicago, IL).

\section{RESULTADOS}

Desde su creación en el año 1994 hasta diciembre del 2004 el Banco y Registro de Donantes Voluntarios de Médula Ósea del Hospital Universitario Virgen de la Arrixaca de Murcia dispone de un total de 3.137 DNE voluntarios registrados y activos, todos ellos tipificados en HLA de clase I (HLA-A y -B) y una parte tipificados en HLA de clase II por baja o por alta resolución (HLA-DRB1, -DRB3, -DRB4, DRB5 y -DQB1, y en algunos casos DPB1) según el momento de producirse una búsqueda de DNE. De esta manera, el registro consta de un total de 345 DNE tipificados en HLA de clase I y II por análisis ADN de baja resolución y 168 DNE tipificados mediante análisis de alta resolución, incrementando de forma exponencial las determinaciones de alta resolución, después de los requerimientos y recomendaciones mínimas para la búsqueda de DNE de la Comisión Nacional de Progenitores hematopoyéticos (febrero 2005) (1).

\section{DISCUSIÓN}

Exponemos un estudio de la procedencia de estos DNE voluntarios. Para ello, agrupamos a éstos según las seis Áreas de Salud en que esta dividida la Comunidad Autónoma de Murcia, como se muestra en la tabla I.

Evidentemente, la zona de mayor densidad poblacional correspondiente con la capital regional (Área I) es la que más DNE aporta a este registro $(28,7 \%)$. También es reseñable la gran proporción $(22,7 \%)$ de DNE aportados por el Área III (zona de Lorca), con el Área II aportando un 18,4\% de DNE (zona de Cartagena). Por lo tanto, entre las 3 áreas que engloban las 3 ciudades más pobladas de la región (Murcia, Cartagena y Lorca) suponen aproximadamente el $70 \%$ de DNE existentes en el registro.

Como se observa la contribución de otras regiones no es desdeñable $(11,7 \%)$, por lo que a continuación se analiza la procedencia de estos 368 donantes (Tabla I). 
TABLA I

PROCEDENCIA DE DMOS SEGÚN LAS ÁREAS DE SALUD DE LA COMUNIDAD AUTÓNOMA DE LA REGIÓN DE MURCIA Y LA APORTACIÓN DE LAS PROVINCIAS LIMÍTROFES

Procedencia de los DMOS

DMOS

$n=3137(\%)$

ÁREA I (Murcia-área metropolitana)

$901(28,7)$

ÁREA II (Campo de Cartagena)

$580(18,4)$

ÁREA III (Campo de Lorca)

$711 \quad(22,7)$

ÁREA IV (Comarca del Noroeste)

200

ÁREA V (Comarca del Altiplano-Yecla)

$(6,4)$

ÁREA VI (Vega del Segura-Comarca Oriental)

Otras Provincias:

Provincia de Granada

Provincia de Alicante

Provincia de Almería

Provincia de Albacete

Provincias no limítrofes

$19(0,6)$

DMO: Donante de médula ósea.

Las provincias limítrofes que más aportan al registro son Alicante $(3,9 \%)$ y Granada $(5,1 \%)$. El porcentaje de la primera es lógico debido a que la vega baja del Segura con capital en Orihuela se encuentra a tan sólo $30 \mathrm{~km}$ de la capital murciana, siendo también una zona densamente poblada. La importante aportación de la provincia de Granada al registro, creemos que se debe a la localización de la Fundación Española para la Lucha contra la Leucemia, por su labor informativa para el reclutamiento de DNE voluntarios, radicada en Caravaca de la Cruz, cercana geográficamente a la comarca granadina de Baza. En cuanto a los DNE de la provincia de Almería (1,9\%), éstos son la mayoría del término municipal de Huercal-Overa, localidad fronteriza con la región de Murcia. Por último, destaca la baja aportación de la provincia de Albacete $(0,3 \%)$, sin embargo, no es extraño debido a la baja densidad poblacional de esta provincia y a su distancia de esta región de los núcleos poblacionales.

Por último, también analizamos la relación de número de DNE obtenidos anualmente con el número de búsquedas que se producen en cada año, con un total de 680 búsquedas de DNE solicitadas por la Fundación Josep Carreras en diez años.

Como se puede observar, la evolución a lo largo de los años del número de DNE nuevos anuales es algo irregular tendente al crecimiento (Fig. 1). De reseñar es el gran número de DNE de los años $1997(n=503)$ y $1998(n=429)$. Esta irregularidad anual puede ser explicada por determinados eventos sociales, como la búsqueda de DNE para un paciente concreto, generalmente infantil, al que se da más difusión en los medios de comunicación y, por consiguiente, una mayor alarma social sobre el hecho de la donación.

Se puede apreciar que en este último año 2004 ha habido un aumento considerable en el número de nuevos DNE ( $\mathrm{n}=$ 445), hecho que esperamos siga produciéndose en los años venideros.

En cuanto al número de búsquedas que se producen al año, se observa un aumento permanente desde la constitución del Banco en el año 1994, con una subida realmente muy significativa también en este último año $(\mathrm{n}=147)$, con casi un incremento del $50 \%$ de búsquedas de DNE solicitadas con respecto

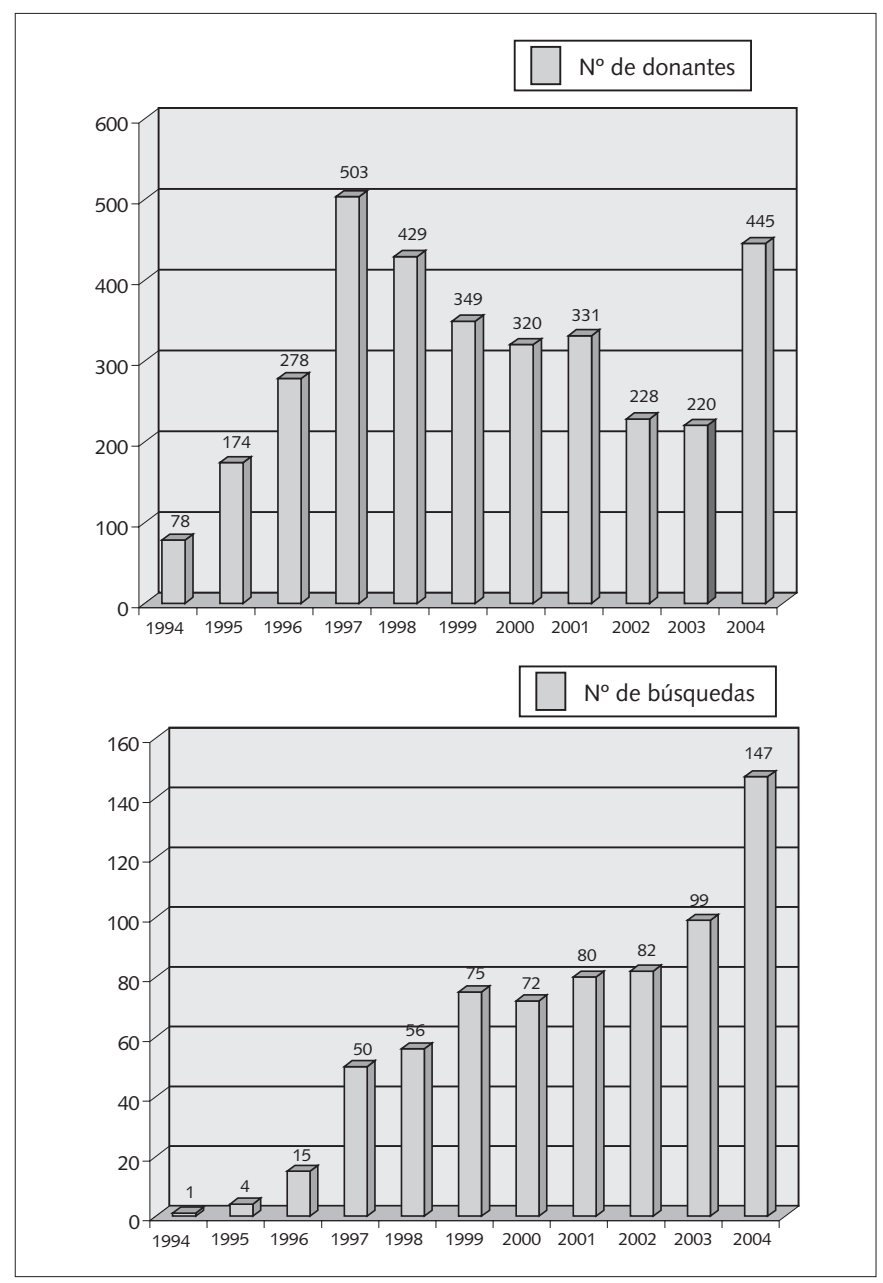

Fig. 1. Evolución del número de donantes voluntarios obtenidos por año (parte superior), así como el número de búsquedas que se producen anualmente (parte inferior).

a las realizadas el año anterior (Fig. 1). Hecho que es constante para el año 2005, en el momento de realización de este estudio. 
Además, antes del establecimiento de nuestro registro (1994), parte de los DNE murcianos eran tipificados en HLA de clase I en Barcelona, y estamos recuperando todos esos DNE murcianos en las posteriores ampliaciones de tipaje solicitadas, por lo que estimamos que al final del año 2006 podemos alcanzar una cifra de entre 4.000 y 5.000 DNE murcianos.

En resumen, la actividad de este banco crece de forma palpable, con la esperanza de vida que ello conlleva y todo ello gracias a la generosidad de muchos. Desde aquí animamos a que la filantropía siga y así poder dar una salida a miles de pacientes, pues hoy por hoy, el trasplante de médula ósea es una de las mejores soluciones terapéuticas para la curación total de la leucemia.

\section{Bibliografía}

1. Anasetti C. Advances in unrelated donor hematopoietic cell transplantation. Haematologica 2003; 88: 246-249.

2. Hurley CK, Baxter-Lowe LA, Logan B, Karanes C, Anasetti C, Weisdorf D, et al. Nacional Marrow Donor Program HLA-matching guidelines for unrelated marrow transplants. Biol Blood Marrow Transplant 2003; 6: $10-15$.

3. Flomenberg N, Baxter-Lowe LA, Confer D, Fernández-Viña M, Filipovich A, Horowitz M, et al. Impact of HLA class I and class II high-resolution matching on outcomes of unrelated donor bone marrow transplantation: HLA-C mismatching is associated with a strong adverse effect on transplantation outcome. Blood 2004; 104: 1923-1930.

4. Kollman C, Howe CW, Anasetti C, Antón JH, Davies SM, Filipovich $\mathrm{AH}$, et al. Donor characteristics as risk factors in recipients after transplantation of bone marrow from unrelated donors: the effect of donor age. Blood 2001; 98: 2043-2451.

5. Ottinger HD, Beelen DW, Elmaagacli AH, Peceny R, Grosse-Wilde H. Hematopoietic stem cell transplantation: in patients above 40 years

\section{AGRADECIMIENTOS}

El primer firmante del artículo es receptora de una Beca de Formación Investigadora en proyectos de xenotrasplante de órganos de la Fundación Séneca (00699/XENI/04). También queremos agradecer la colaboración de la Fundación CajaMurcia y la Red de Grupos de Investigación (G03/104, Inmunología del Trasplante), Ministerio de Sanidad y Consumo. Agradecer a todos los donantes voluntarios por su altruismo y solidaridad, sin cuya aportación no se hubiera podido constituir este Banco. También queremos agradecer especialmente a Maria José Sanchís Morell, José Miguel Alemany Puig y Manuela López Sánchez por su excelente labor técnica y su apoyo constante, así como a todo el personal del Servicio de Inmunología.

young HLA-matched unrelated donors should be preferred to HLA-identical sibling donors (abstract). Blood 2003; 102: 489a.

6. Atkinson K, Horowitz MM, Gale RP, van Bekkum DW, Gluckman E, Good RA, et al. Risk factors for chronic graft-versus-host disease after HLA-identical sibling bone marrow transplantation. Blood 1990; 15: 2459-2464.

7. Sierra J, Storer B, Hansen JA, Bjerke JW, Martin PJ, Petersdorf EW, et al. Transplantation of marrow cells from unrelated donors for treatment of high-risk acute leukaemia: the effect of leukemic burden, donor HLAmatching, and marrow cell dose. Blood 1997; 89: 4226-4235.

8. Muro M, Marín L, Torío A, Moya-Quiles MR, Minguela A, Rosique J, et al. HLA polymorphism in the Murcia Population (Spain) in the Cradle of the Archaeologic Iberians. Human Immunol 2001; 62: 910-921.

9. Muro M, Moya-Quiles MR, Marín L, Torío A, Vallejo C, Moraleda JM, et al. Report of recombinations between HLA locus within two families: Utility of high resolution typing. Clin Transplant 2002; 16: 329-333. 